\title{
A Generic T-tail Transport Airplane Simulation for High-Angle-of-Attack Dynamics Modeling Investigations
}

\author{
Kevin Cunningham, ${ }^{1}$ Gautam H. Shah ${ }^{2}$ \\ NASA Langley Research Center, Hampton, VA, 23681 \\ Melissa A. Hill, ${ }^{3}$ Brent P. Pickering ${ }^{4}$ \\ Unisys Corporation, NASA Langley Research Center, Hampton, VA, 23681 \\ Jonathan S. Litt, ${ }^{5}$ \\ NASA Glenn Research Center, Cleveland, OH, 44135 \\ and \\ Scott B. Norin ${ }^{6}$ \\ Vantage Partners, LLC, Cleveland, $\mathrm{OH}, 44142$
}

\begin{abstract}
A preliminary simulation of a generic T-tail transport airplane configuration has been developed at the National Aeronautics and Space Administration Langley Research Center. The primary purpose of this piloted simulation is to assess aerodynamic model fidelity requirements for training airline pilots to recognize and recover from full-stall flight conditions in a T-tail airplane. As a result, significant flexibility has been designed into the flight dynamics model. The flight dynamics model is based on newly acquired static and dynamic stability and control data from sources that include: wind tunnel, water tunnel, and computational fluid dynamics. Preliminary results for initial stall show an unstable stall pitch break (if the stick pusher is inhibited), un-commanded motions due to stall asymmetries, significantly reduced dynamic roll stability, and decreased control effectiveness. Preliminary studies indicated an insensitivity to the fidelity of the pitch damping model.
\end{abstract}

$\begin{array}{llll} & & \text { Nomenclature } \\ \text { ail } & =\text { aileron } & \mathrm{ft} & =\text { feet } \\ \mathrm{b} & =\text { wingspan } & \mathrm{GTT} & =\text { Generic T-tail Transport } \\ \text { CAST } & =\text { Commercial Aviation Safety Team } & \mathrm{g} & =\text { acceleration due to gravity } \\ \mathrm{CFD} & =\text { computational fluid dynamics } & \mathrm{Ixx} & =\text { moment of inertia about longitudinal axis } \\ \mathrm{CG} & =\text { center of gravity } & \mathrm{Iyy} & =\text { moment of inertia about lateral axis } \\ \mathrm{C}_{\mathrm{L}} & =\text { lift coefficient } & \text { Izz } & =\text { moment of inertia about normal axis } \\ C_{l} & =\text { rolling moment coefficient } & \text { KCAS } & =\text { knots calibrated airspeed } \\ C_{m} & =\text { pitching moment coefficient } & \text { N1 } 1 \text { Left } & =\text { Left engine fan speed } \\ C_{n} & =\text { yawing moment coefficient } & \text { NASA } & =\text { National Aeronautics and Space Administration } \\ \bar{c} & =\text { mean aerodynamic chord } & \text { NTSB } & =\text { National Transportation Safety Board } \\ \text { deg } & =\text { degrees } & \text { Nz } & =\text { normal load factor } \\ \text { FAA } & =\text { Federal Aviation Administration } & & \end{array}$

\footnotetext{
${ }^{1}$ Senior Research Engineer, Flight Dynamics Branch, Mail Stop 308, AIAA Senior Member.

${ }^{2}$ Senior Research Engineer, Flight Dynamics Branch, and Manager, TASA, MS 308, AIAA Senior Member.

${ }^{3}$ Software Engineer, NASA Langley Research Center, Mail Stop 169.

${ }^{4}$ Software Engineer, NASA Langley Research Center, Mail Stop 169.

${ }^{5}$ Control Systems Engineer, Intelligent Control and Autonomy Branch, Mail Stop 77-1, AIAA Associate Fellow.

${ }^{6}$ Aerospace Engineer, Intelligent Control and Autonomy Branch, 3000 Aerospace Parkway, Brook Park, Ohio, AIAA Member.
} 


$\begin{array}{llll}\mathrm{p}, \mathrm{q}, \mathrm{r} & =\text { roll, pitch, yaw body axis rates } & \Delta & =\text { incremental change } \\ \hat{p}, \widehat{q}, \hat{r} & =p b / 2 V, q \bar{c} / 2 V, r b / 2 V & \alpha & =\text { angle of attack } \\ \text { rad } & =\text { radian } & \beta & =\text { angle of sideslip } \\ \text { rud } & \text { rudder } & \dot{\beta} & =\text { sideslip angle rate of change } \\ \mathrm{S} & =\text { wing area } & \delta_{\mathrm{a}} & =1 / 2(\text { right aileron }- \text { left aileron) } \\ \mathrm{SAS} & =\text { Stability Augmentation System } & \delta_{\mathrm{e}} & =\text { elevator deflection } \\ \mathrm{SDAB} & =\text { Simulation Development and Analysis Branch } & \delta_{\mathrm{r}} & =\text { rudder deflection } \\ \mathrm{SE} & =\text { Safety Enhancement } & \delta_{\mathrm{spL}} & =\text { left spoiler deflection } \\ \text { sec } & =\text { seconds } & \delta_{\mathrm{spR}} & =\text { right spoiler deflection } \\ \text { sim } & =\text { simulation } & \theta & =\text { pitch attitude angle } \\ \text { TASA } & =\text { Technologies for Airplane State Awareness } & \phi & =\text { bank angle } \\ \text { TER, TEL } & =\text { Trailing Edge Right, Trailing Edge Left } & & \\ \text { TEU, TED } & =\text { Trailing Edge Up, Trailing Edge Down } & & \\ \text { T-MATS } & =\text { Toolbox for Modeling and Analysis of Thermodynamic Systems } \\ \text { V } & =\text { velocity }\end{array}$

\section{Introduction}

$\mathrm{I}_{\mathrm{a}}^{\mathrm{n}}$ n-flight loss-of-control has historically been a major contributor to the fatal accident rate of commercial transport airplanes. ${ }^{1}$ A key intervention strategy that aims to reduce the occurrence of loss-of-control accidents is the improvement of flight simulations to allow for more accurate representation of stalls, loss-of-control, and upset scenarios. ${ }^{2}$ The potential uses for the improved simulations include control law analysis, advanced flight display design, mishap investigation, engineering support, and training for recognition and recovery from full stall conditions. The National Aeronautics and Space Administration (NASA) published research on this topic in 2002. ${ }^{3}$ At that time, a NASA/Boeing partnership, operating under NASA's Aviation Safety Program, performed extensive aircraft accident analysis, simulation technology analysis, ground-based aerodynamic testing, and flight simulation development to address the potential for improving transport airplane simulations for use in stall and upset conditions. ${ }^{4}$ The focus vehicle for that configuration was a transport airplane with a conventional horizontal tail (mounted low relative to the vertical tail, as opposed to a T-tail configuration).

In 2009, the National Transportation Safety Board (NTSB) investigated a fatal mishap involving in-flight loss of control of a twin engine turbo-prop commercial transport airplane. The NTSB determined the probable cause of that mishap to be an inappropriate response to a stall warning system, which resulted in an aerodynamic stall from which the airplane did not recover. In their investigative report, ${ }^{5}$ the NTSB cited research by NASA/Boeing and others relating to modeling and simulation of stalled flight conditions. One of the report's recommendations (A-10-24) called for defining simulator fidelity requirements and addressing other requirements to support full stall recovery training during flight simulator training.

After publication of NTSB recommendation A-10-24, a public law (111-216) was passed in 2010, which requires stall training for all part 121 air carriers. To meet the requirements of that law, the Federal Aviation Administration (FAA) developed rules and regulations that will result in full stall simulator training beginning in $2019 .{ }^{6}$ During this developmental phase, the $\mathrm{FAA}^{7}$ and others have investigated model fidelity requirements relating to the use of aerodynamic models for simulation of transport airplane stall characteristics. That investigation focused on several stall models representing an airplane with wing mounted engines and a low- horizontal-tail. Expanding research efforts to include study of stall model fidelity pertaining to airplanes with T-tail aft twin engine configurations was identified as a safety enhancement element by the Commercial Aviation Safety Team (CAST).

CAST is a government-industry partnership with a strategy to achieve their goal of reducing commercial aviation fatality risk. CAST working groups use accident analysis to identify plans for potential changes to prevent accidents. These formally adopted plans take the form of Safety Enhancements (SE). SE-209 is the specific CAST researchbased Safety Enhancement that includes an element to investigate flight dynamics models of a T-tail airplane with aft twin engines. 
Recent research relating to extending aerodynamic model envelopes for T-tail airplane stall training has been conducted by the University of Toronto Vehicle Simulation Laboratory. ${ }^{8}$ That research leveraged a proprietary configuration's existing ground and flight test data, along with parameter estimation techniques to extend a flight dynamics model into the post-stall regime.

To contribute toward the model fidelity research goals of SE-209, this project has conducted dedicated high-angleof-attack ground testing of a generic T-tail transport (GTT) airplane configuration. ${ }^{9}$ The testing used multiple experimental and computational fluid dynamics (CFD) facilities. The test techniques that were used included static and dynamic force and moment testing as well as flow visualization. Data from these tests were used to develop a sixdegree-of-freedom simulation model.

This paper will present a summary of some of the key data, a brief description of the simulation and preliminary results. Because this research is ongoing, model forms will evolve, so the results cannot be considered final.

\section{Descriptions}

\section{A. Simulation Software}

The GTT simulation software was implemented in object-oriented C++ using the Langley Standard Real-time Simulation in $\mathrm{C}++(\mathrm{LaSRS}++)$ framework. ${ }^{10} \mathrm{LaSRS}++$ is used by the Simulation Development and Analysis Branch (SDAB) at NASA's Langley Research Center in Hampton, Virginia, to build six-degree-of-freedom simulation products for high-fidelity research simulators. ${ }^{11}$ LaSRS++ was designed to encourage software reuse and to enable rapid prototyping of vehicle models by providing a large number of generic components. The GTT simulation inherits basic functionality from foundational transport aircraft software components. This functionality includes systems for modeling aerodynamics, flight control, landing gear, mass properties, navigation, propulsion, and stall warning. The commands output from the flight control laws drive a set of control surface models including a stabilizer, elevators, flaps, ailerons, spoilers, and rudders. The navigation system uses two air data systems and receivers for standard navigational radio signals. During operations with cockpit hardware, the navigation system is integrated with a flightrated flight management computer and a navigation database of the continental United States. The propulsion system integrates models of two 14,000-pound-thrust-class turbofan engines developed at the NASA Glenn Research Center in Cleveland, Ohio. The stall warning system includes logic for driving a speed tape on the primary flight display, a stick pusher, and a stick shaker on the control column. The GTT simulation is executed at a frame rate of 50 Hertz on specialized Linux host computers equipped with time code generator cards. The simulation software supports both batch/desktop or full human-in-the-loop cockpit hardware interfaces.

\section{B. Simulation Hardware}

The SDAB designs, operates, and maintains a wide range of flight simulation facilities. The Cockpit Motion Facility is a multifaceted flight simulation research laboratory designed to support aeronautics and space flight vehicle research studies in which motion cues are critical to the realism of the experiments being conducted. This facility is designed around a high-performance, 76-inch, six-degree-of-freedom, hydraulically-actuated synergistic hexapod motion system. Four fixed-base simulator sites house three full-scale flight deck simulator cockpits, which can be operated on the fixed-base sites or moved from the fixed-base sites to the motion system using an overhead bridge crane system. ${ }^{12}$

The GTT simulation uses the facility's Integration Flight Deck Simulator shown in Figs. 1 and 2. It is a full-scale, full-mission high-fidelity flight deck simulator with two crew and three observer seats. It is configured as a replica of a next-generation transport class aircraft with a full suite of flight deck panels, a center aisle stand and throttle quadrant, and flight management computer. With fully programmable wheel/column/pedal control inceptors and heads-down displays, the simulator can support any number of aircraft models, including the GTT model. 
The cockpit control inceptors consist of two sets of wheel-columns and pedals that are fully back-driven in all axes via an electric control loading system. This provides dynamic feedback to the pilots with force-feel profiles tuned for the GTT vehicle. In addition to simulating flight control feedback, the control loader is used to simulate the stick pusher mechanism. Each column is also equipped with a hardware stick shaker that is triggered from the vehicle's stall warning system.

The out-the-window view is provided by a panorama display system with a 200 degree horizontal by 40 degree vertical field of view. A detailed database of the Dallas-Fort Worth International Airport is used for this project. Heads-down displays are comprised of six raster displays including dual next-generation-style primary flight displays, dual navigation displays, a custom engine instrumentation and alerting display, and a custom research display that includes cockpit control positions and stall/upset related parameters. Two electronic flight bags are used for displaying an aft view of the GTT outer mold line and dynamically displaying the control surface positions and engine pressure ratios. Cockpit audio cues are provided by a digital sound system.

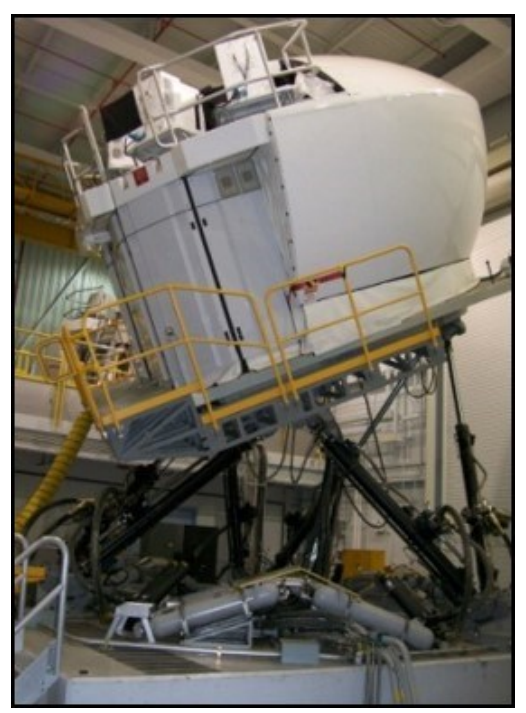

Fig. 1 A photo showing the exterior of the Integration Flight Deck simulator mounted on the Cockpit Motion Facility's hexapod motion base.

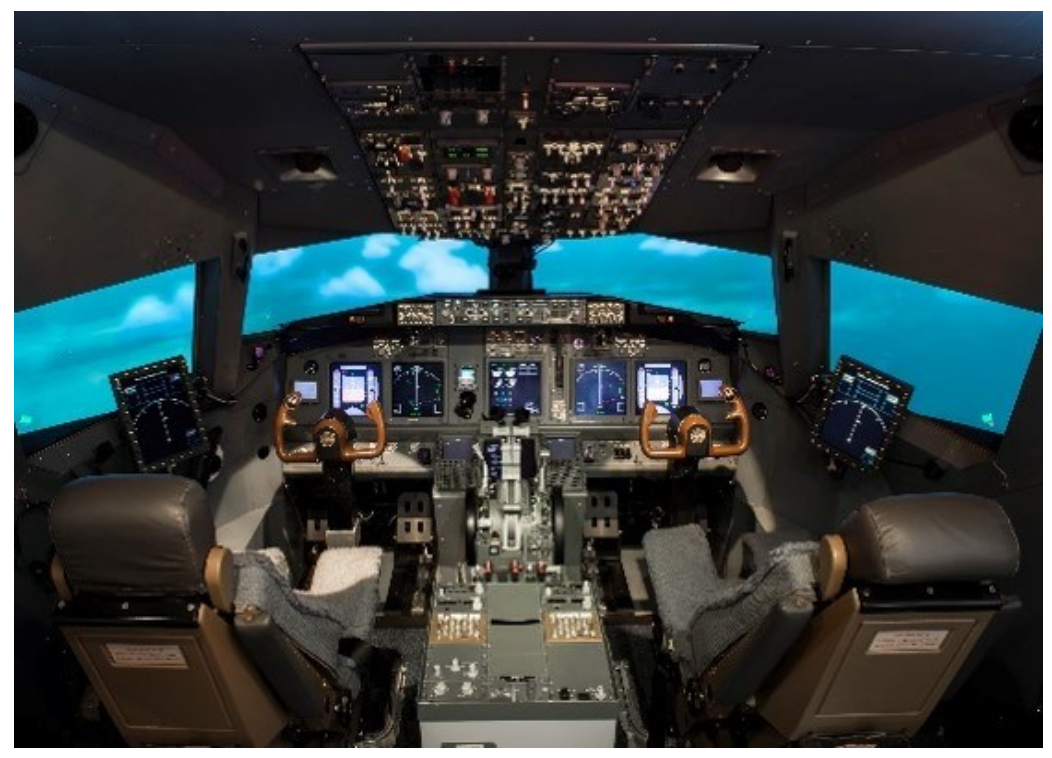

Fig. 2 A photo showing the interior of the Integration Flight Deck simulator cockpit. 


\section{Simulation Mass and Geometric Properties}

The GTT simulation model represents a T-tail transport airplane with a 76 -foot wingspan and 98 -foot fuselage length. The nominal center of gravity (and moment reference location) is the $25 \%$ mean aerodynamic chord location, unless otherwise noted. The nominal mass properties configuration is intended to represent the airplane at a light weight (6,000 pounds fuel). A light weight was used to allow simulation of, potentially, the worst case dynamics associated with minimal moments of inertia. Aerodynamic reference dimensions and GTT baseline mass properties are shown in Tables 1 and 2. A sketch of the GTT geometric configuration (and control surface arrangement) is shown in Fig. 3 and a wind-tunnel model is shown in Fig. 4. Drawings with higher level of dimensional accuracy and detail are shown in Ref. 9.

Table 1. Aerodynamic reference dimensions

\begin{tabular}{|c|c|c|}
\hline $\begin{array}{c}\text { Aerodynamic } \\
\text { Reference }\end{array}$ & Symbol & $\begin{array}{c}\text { Full Scale } \\
\text { Dimension }\end{array}$ \\
\hline Mean Aerodynamic Chord & $\bar{c}$ & 11.07 feet \\
\hline Wingspan & $\mathrm{b}$ & 75.98 feet $^{2}$ \\
\hline Wing Area & $\mathrm{S}$ & 754.32 feet $^{2}$ \\
\hline
\end{tabular}

Table 2. Mass properties

\begin{tabular}{|c|r|c|}
\hline Parameter & \multicolumn{1}{|c|}{ Quantity } & Units \\
\hline Weight & 55,847 & pounds \\
\hline Ixx & 175,849 & slug-foot $^{2}$ \\
\hline Iyy & $1,114,179$ & slug-foot $^{2}$ \\
\hline Izz & $1,266,792$ & slug-foot $^{2}$ \\
\hline
\end{tabular}

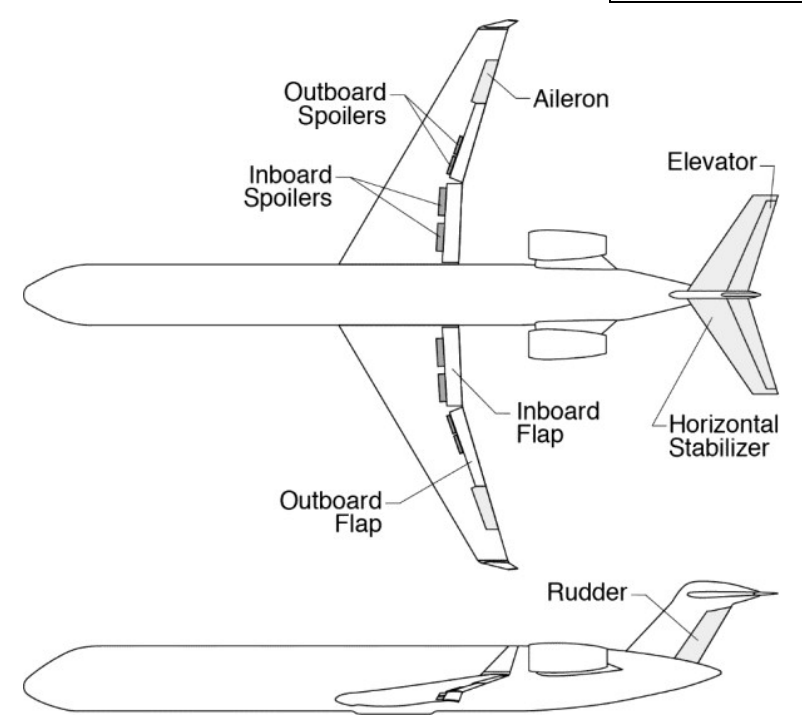

Fig. 3 A sketch of the GTT configuration showing control surface arrangement.

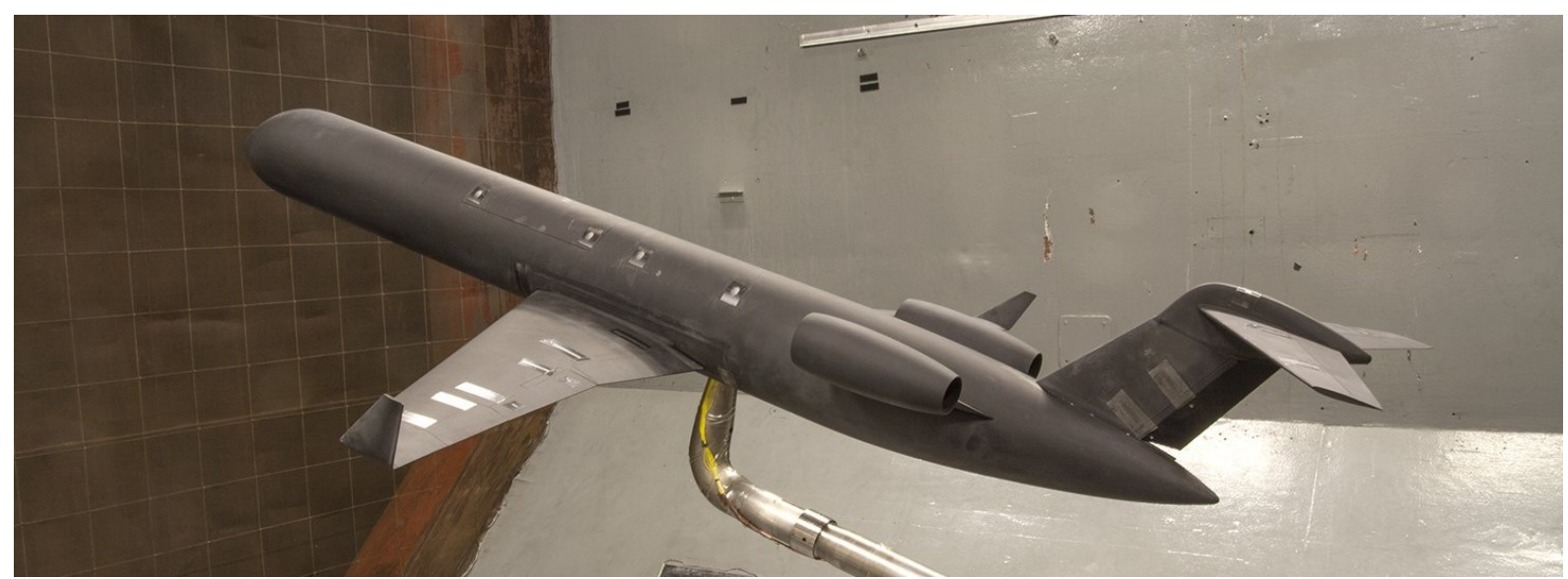

Fig. 4 A photo of a 5.7\% scale model mounted in a low speed wind tunnel. 


\section{Flight Control Laws}

The flight control system in the GTT simulation is intended to represent an airplane with conventional, irreversible, hydro-mechanical flight controls. Force-feel characteristics are implemented in cockpit control loader systems as functions of hardware displacement and dynamic pressure. Control surface positions are modeled as first-order lags on the control surface commands, subject to rate and position limiting. Pitch trim is accomplished via a thumb switch on the control wheel, which drives the horizontal stabilizer.

The pitch and yaw flight control laws are simple, direct schedules of surface commands as a function of control inceptor position. The lateral control law is slightly more complex than the pitch and yaw laws because it involves aileron-spoiler blending. The aileron and spoiler command schedule is shown in Fig. 5. Note that positive control wheel deflection is to the right and that "aileron deflection" is defined to be $\delta_{a}=1 / 2$ (Right Aileron Left Aileron). Control surface deflection ranges are shown in Table 3. Note that the maximum roll spoiler deflection command is limited to 30 degrees and the maximum symmetric spoiler command (speed brake function) is also limited to 30 degrees. This is to ensure that the 60 degree control surface limit shown in Table 3 is not exceeded. .

Reference 9 notes that at normal, slow cruise angle of attack, the $C l_{\beta} / C n_{\beta}$ ratio is high. From Table 2 it can be seen that the roll-to-yaw inertia ratio is low. Hence, a high, roll-dominant $\phi / \beta$ ratio was observed. Because the openloop airplane also has a lightly damped Dutch Roll mode, a significant roll ratchet was observed during roll maneuvers. To improve the flying qualities, yaw axis stability augmentation was developed. The simulation has the option to use an aileron-rudder interconnect and/or a generic $\dot{\beta}$ yaw damper system. ${ }^{13}$ These systems significantly improved the Dutch Roll damping and provided a classic first-order roll response. The effect of the yaw stability augmentation system on roll response to an aileron step input is shown in Fig. 6.

In the current version of the stall protection system, activation is only dependent upon angle of attack. When the angle of attack exceeds the activation threshold, the control loader system uses a neutral shift functionality to abruptly shift the control column forward. The amount of shift was tuned to attain a target-normal load factor of approximately $0.5 \mathrm{~g}$. The override force for the stick pusher is nominally 65 pounds. The stall protection activation threshold is nominally 10 degrees angle of attack. The stall warning stick shaker is currently set for activation at 7.5 degrees angle of attack. Many of the system's thresholds and parameters are configurable at the simulation operator's station.

Table 3. Control surface deflection ranges.

\begin{tabular}{|c|c|}
\hline Control Surface & Deflection Range, degrees \\
\hline Elevator & -20 (TEU) to +20 (TED) \\
\hline Stabilizer & -10 (TEU) to +5 (TED) \\
\hline Spoilers & 0 to 60 (TEU) \\
\hline Ailerons & $-25($ TEU) to $+25($ TED) \\
\hline Rudder & -30 (TER) to +30 (TEL) \\
\hline
\end{tabular}

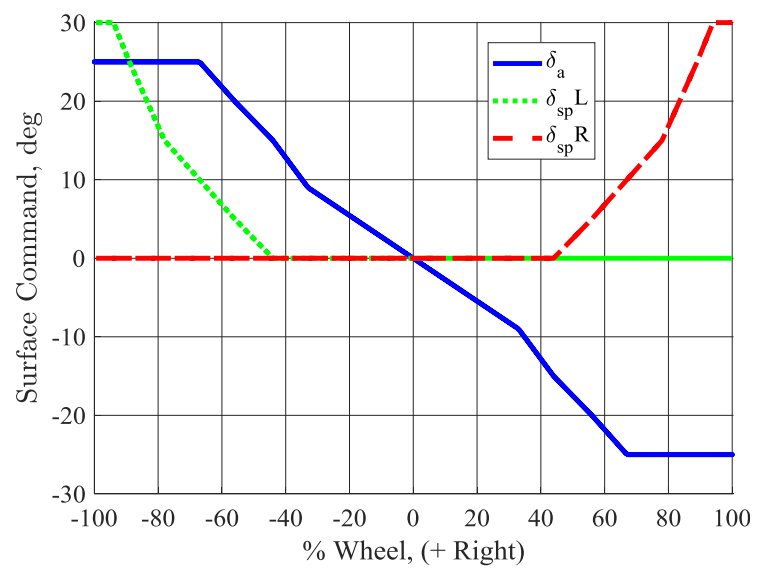

Fig. 5 The aileron and spoiler schedule (as a function of wheel position) is shown.
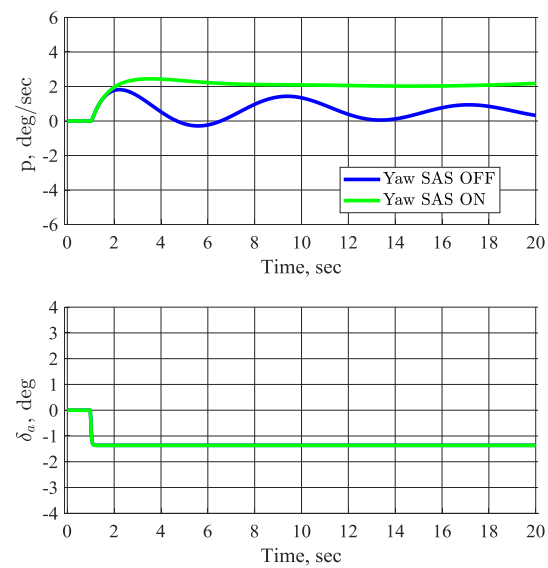

Fig. 6 Roll rate response to aileron step input with the yaw stability augmentation system on and off. 


\section{E. Propulsion System}

The propulsion system model consists of two high-bypass turbofan engines in the 14,000-pound-plus thrust class range, typical of those on regional jet aircraft today. The engines were initially modeled in Simulink ${ }^{\circledR}$ using the opensource Toolbox for the Modeling and Analysis of Thermodynamic Systems (T-MATS). ${ }^{14}$ This toolbox enabled the development of a non-linear, physics-based Component Level Model (CLM) ${ }^{15}$ that was subsequently matched to data generated using the Numerical Propulsion System Simulation. ${ }^{16}$ The CLM provides an acceptable level of fidelity for preliminary control design. ${ }^{17,18}$ The addition of a Min-Max Proportional-Integral controller, typical of those on turbofan engines, ${ }^{19}$ ensured appropriate closed-loop throttle-to-thrust operation for the nominal engine. This established the baseline full-envelope performance of the model.

An engine is designed to be robust to uncertainties and variations it might experience during normal use, including such things as airflow distortion at the inlet, wear and tear, manufacturing tolerances, etc. ${ }^{20}$ However, for commercial engines, which are designed to operate over a limited range of angle of attack, these expected variations are bounded. As angle of attack gets larger, the fan performance deteriorates, resulting in reduced thrust and stability. ${ }^{21}$ Upset conditions and unusual attitudes, including high angle of attack and sideslip, are far enough from nominal that real engine performance may be impacted, and the baseline model does not capture these effects.

The T-MATS CLM contains simplifications that are reasonable approximations under nominal conditions, but not for those under investigation. These simplifications include the use of 0-dimensional or lumped component models (compressors, turbines), and the simplifying assumption that airflow into the engine is ideal. Thus, the fidelity of the engine model needs to be increased so that off-nominal behavior due to high angle of attack and sideslip could be represented accurately.

To address this in future enhancements of the engine model, research is ongoing. A variety of approaches are being used to augment the model in order to capture the desired effects, including volume dynamics, which provides higher dimensional flow calculations; stage-by-stage component modeling; and parallel flow path modeling. ${ }^{22}$ For example, these techniques are able to represent flow variations within the engine due to distortion at the inlet, which can result in severely degraded operation and even loss of thrust. ${ }^{2,23}$

Additionally, $\mathrm{CFD}^{24-26}$ is being used to determine the non-uniform pressures at the engine face due to high angle of attack, and, for aft-fuselage mounted engines, wake from the wing. This will result in a physics-based, closed-loop engine model whose inlet conditions are a function of the aircraft wind-incidence angle and flight condition, and that will respond realistically to these conditions as they propagate through the engine. 


\section{Results}

\section{A. Aerodynamic Model}

This report references the GTT simulation aerodynamic model version 301.171108. The stability and control characteristics represented in this model are discussed in detail in Ref. 9 and will not be repeated in this report. This simulation model is intended to represent a generic T-tail airplane in the flaps-up configuration at subsonic (Mach number $<0.6$ ) speeds. The focus of the aerodynamic fidelity is placed on the stall and post-stall stability and control characteristics.

A common, superposition-of-effects approach is used for the computation of total force and moment coefficients. The aerodynamic characteristics representing the various effects were derived from low-speed, low chord-based Reynolds Number wind and water tunnel tests. CFD was used to estimate Reynolds Number corrections, establish trends to blend between tunnel results, and verify tunnel results. The effects represented from these test data are tabulated and accessed for use in the aerodynamic buildup by multi-dimensional linear interpolation functions. Equation 1 is a generalized example of this approach for rolling moment.

$$
\begin{aligned}
C l_{\{t o t a l\}}=C l(\alpha, \beta) & +\Delta C l_{\{a i l\}}\left(\alpha, \beta, \delta_{a}\right)+\Delta C l_{\{r u d\}}\left(\alpha, \beta, \delta_{r}\right)+\Delta C l_{\{s p L\}}\left(\alpha, \beta, \delta_{\{s p L\}}\right) \\
& +\Delta C l_{\{s p R\}}\left(\alpha, \beta, \delta_{\{s p R\}}\right)+\Delta C l_{\{a s y m m e t r y\}}(\alpha, \beta)+C l_{\hat{p}}(\alpha, \hat{p}) \hat{p}+C l_{\hat{r}}(\alpha, \hat{r}) \hat{r}
\end{aligned}
$$

Figure 7 shows the lift and pitching moment characteristics for the GTT simulation model with all controls zero and a center of gravity at $25 \%$ mean aerodynamic chord. Reynolds Number corrections have been applied to the pitching moment characteristic shown in the figure. The purpose of the vertical, dashed reference lines in the figure is to highlight the relationship of the characteristics to the stall warning (stick shaker) activation angle of attack and the stall protection (stick pusher) activation angle of attack. The purpose of the stall warnings and protection system is to protect against unintentionally encountering the unstable pitch up characteristic at 15 degrees angle of attack. This system is designed such that the margin to the unstable pitch break is 15 knots from stick shaker and 5 knots from stick pusher (for static entry conditions).

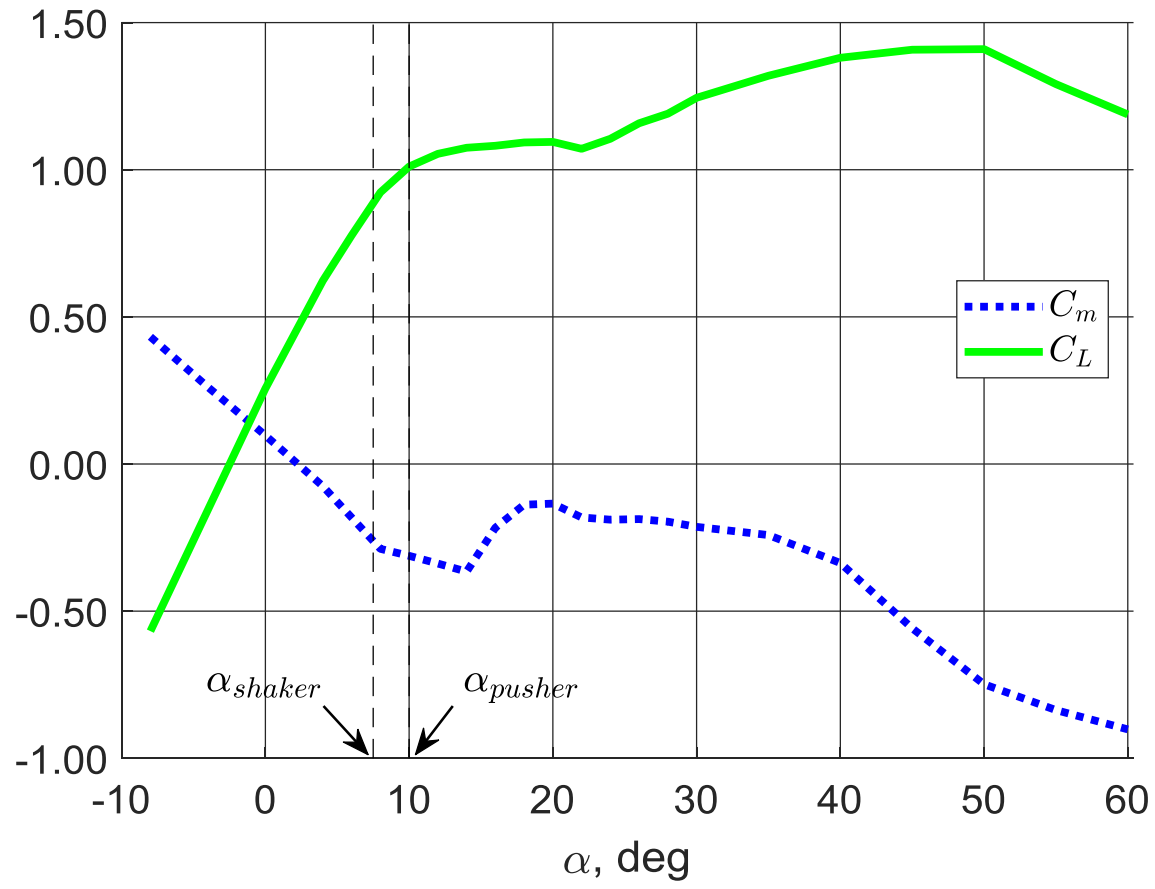

Fig. 7 Pitching moment and lift coefficients are shown for all controls zero. Vertical dashed lines are references for the stall warning and stall protection activation angles of attack. 
Figures 8 to 10 show the pitch, roll, and yaw damping stability derivatives for the GTT simulation model compared with those of the "GTM polysim" model. ${ }^{27}$ The "GTM polysim" is a non-proprietary polynomial approximation of wind tunnel data acquired from a 5.5\% generic transport model which had a (conventional) low horizontal tail. (The data presented in these comparisons represent the dynamic stability derivatives for frequencies corresponding to the Short Period or Dutch Roll dynamic modes as appropriate.)

Figure 8 shows differing trends in $\mathrm{Cm}_{q}$ as angle of attack approaches stall. The GTM model shows a relative minimum damping at 12 degrees angle of attack. The GTT model shows the relative minimum damping at 18 degrees angle of attack. This difference is attributed to the wing wake and horizontal tail interactions occurring at lower angles of attack for the GTM than it does for the GTT. Figure 9 shows, for both models, a rapid decrease in roll damping stability as angle of attack approaches the initial stall. Differences in yaw damping, shown in Figure 10, are generally attributed to differences in the vertical tail sizing and overall lower directional static stability of the GTT relative to the GTM configurations.

Figure 11 highlights some wind-tunnel-based model results for the GTT configuration that are consistent with previous results for a low horizontal tail configuration ${ }^{4}$. In the approach-to-stall angle of attack range, there is a reduction in roll control effectiveness and the development of a roll asymmetry. For the GTT model, roll asymmetry begins at 9 degrees angle of attack, 1 degree prior to onset of stick pusher. Note that roll asymmetry further increases if angle of attack increases beyond stick pusher angle of attack.

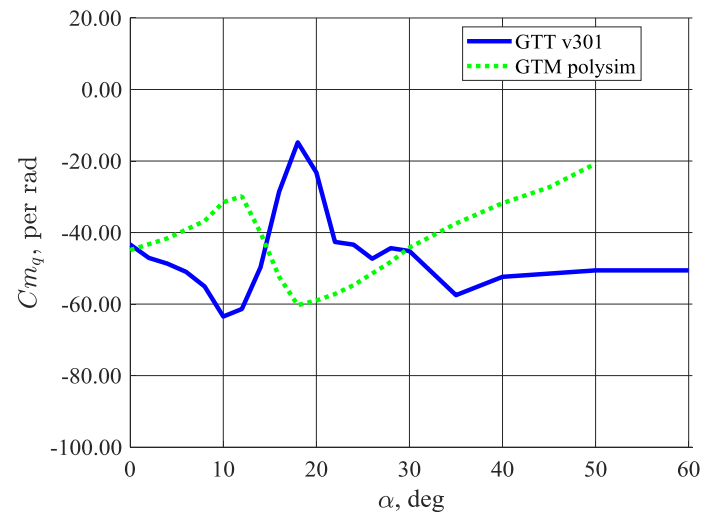

Fig. 8 The GTT pitch damping coefficient is compared with the "GTM poly sim" pitch damping coefficient.

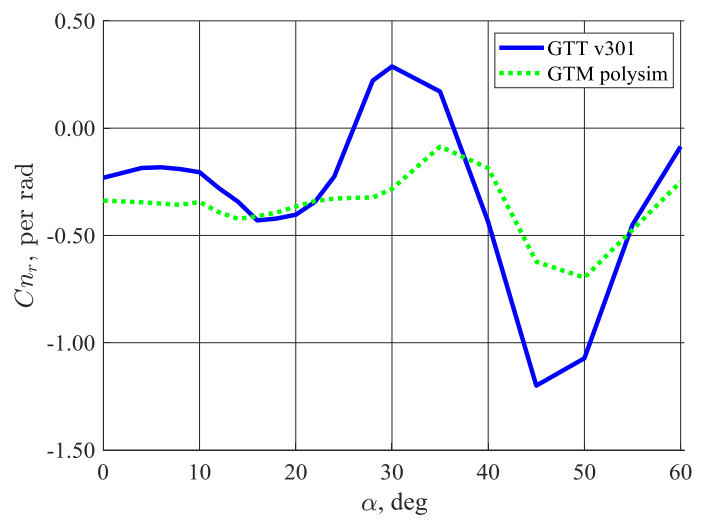

Fig. 10 The GTT yaw damping coefficient is compared with the "GTM poly sim" yaw damping coefficient.

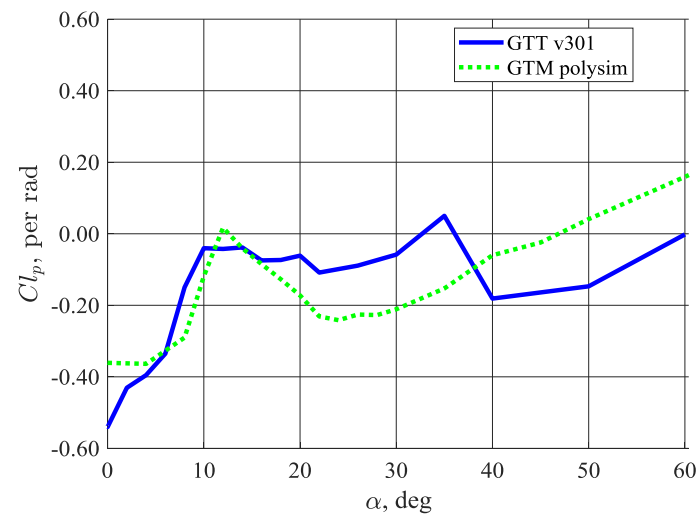

Fig. 9 The GTT roll damping coefficient is compared with the "GTM poly sim" roll damping coefficient.

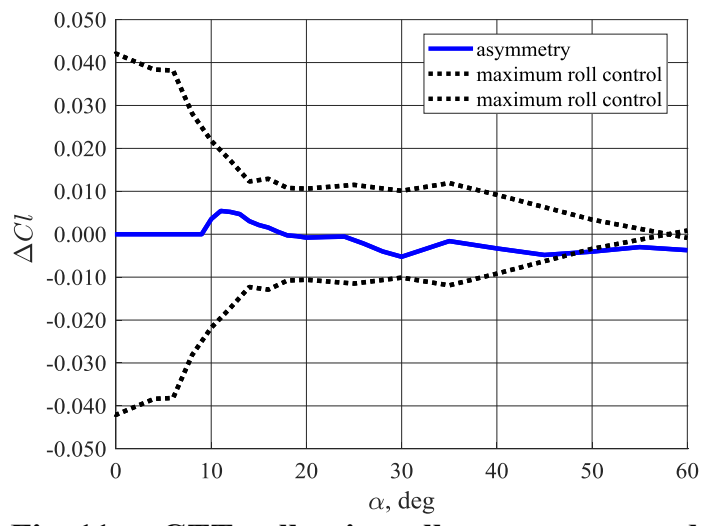

Fig. 11 GTT roll axis stall asymmetry model is compared to maximum roll control power. Note the significant reduction in control power in the approach to stall angle of attack range. 
Figure 12 shows one of the three options that are available in the simulation to represent the pitch damping derivative, $\mathrm{Cm}_{q}$. The model shown in Fig. 12 is based on water tunnel sinusoidal forced oscillation tests for a 5 degree body axis amplitude. Force and moment data were acquired for the single amplitude of oscillation at three frequencies over a wide range of angle of attack. The three frequencies were based on multiples of $0.5,1.0$, and 2.0 times the Short Period dynamic mode frequency. The data for each hysteresis loop were reduced using the single point method. ${ }^{9}$ The results only showed a significant relative variation in $\mathrm{Cm}_{q}$ over a relatively small angle of attack range (14 to 22 degrees). The data were modeled in the simulation as a function of each loop's maximum non-dimensional rate, $\hat{q}=$ $(q \bar{c}) / 2 V$.

Currently, three options are available in the GTT simulation model for the dynamic stability derivatives. The first, which is described above, is nonlinear with both angle of attack and body axis angular rate. The second option is nonlinear with only angle of attack and disregards rate effect, using only the mid-rate characteristic (such as that represented by the green dashed line in Fig. 12). The third option is identical to the second option when below stick shaker angle of attack. Above stick shaker angle of attack, the dynamic stability derivative would be held constant and represents a "hold last value" approach that has been seen in heritage transport airplane training simulation models ${ }^{3}$.

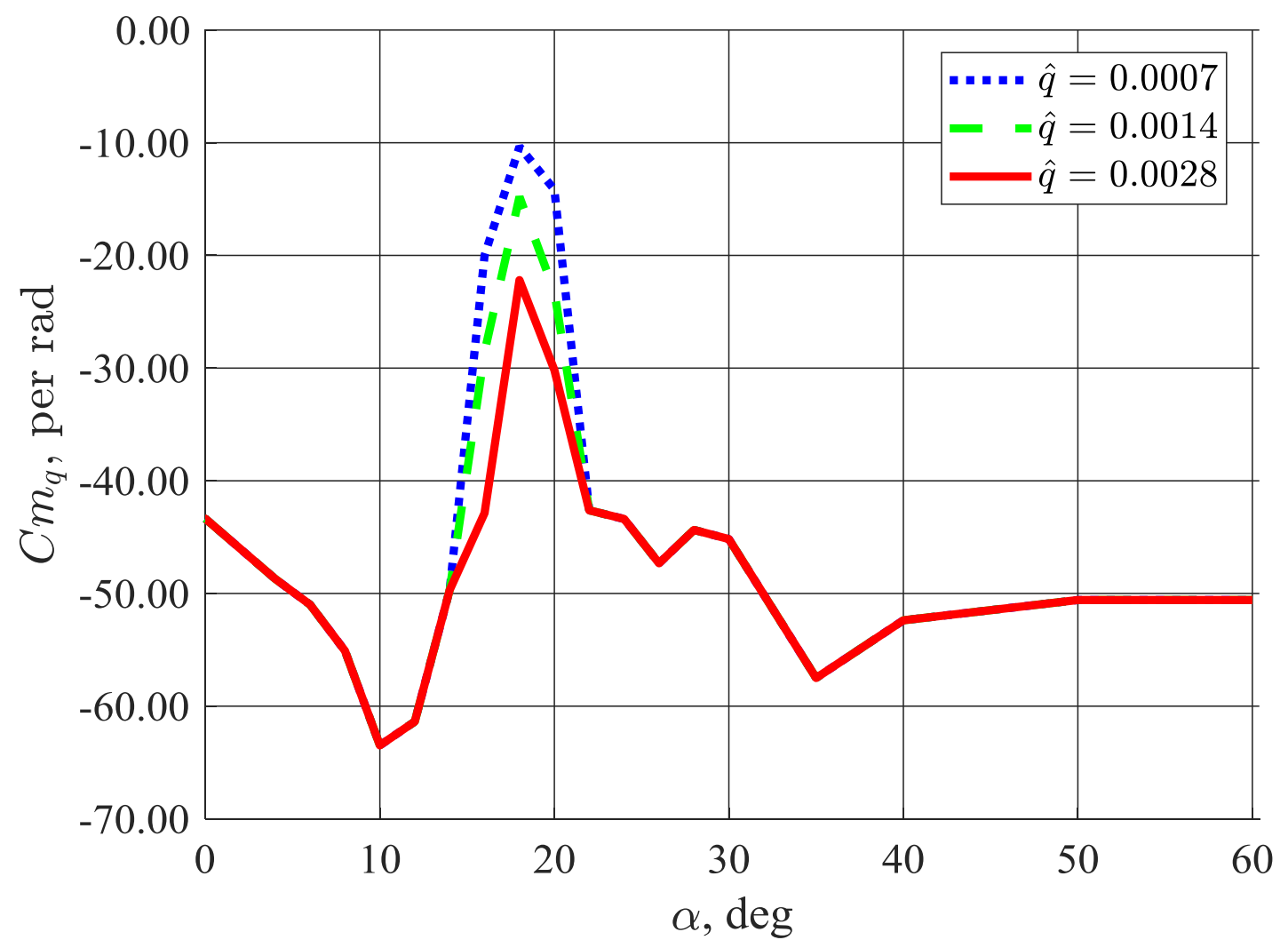

Fig. 12 GTT pitch damping model with nonlinearity in both rate and angle of attack. 


\section{B. Simulation Response}

A simulation study was performed using a "stall pilot" algorithm for run-to-run consistency. The purpose of the study was to assess the integrated simulation response to the unstable stall characteristics in the aerodynamic model. The stall pilot is a simple proportional-integral-derivative controller that provides wheel and column commands in response to pitch attitude and bank angle. The algorithm is initialized with a pre-defined angle of attack at which recovery mode is initiated. In recovery mode, the controller abandons pitch attitude control and switches to angle of attack control. A 7 degree angle of attack was captured during recovery. After the target angle of attack has been tightly maintained for 3 seconds, the controller resumes pitch attitude command tracking.

For this study, the stall protection system (stick pusher) was inhibited. The simulation was trimmed for level flight at 10,000 feet above ground level, at 4 degrees angle of attack (193 KCAS). Trim throttle position was not varied during the profile. Trim with zero elevator was accomplished using -1.6 degrees of stabilizer, which remained constant. The center of gravity was at $25 \%$ mean aerodynamic chord. The stall-pilot algorithm used a 10 degree pitch attitude capture to establish a reasonable deceleration rate. For this investigation, the algorithm was programmed to freeze the pitch control inputs at stall pitch-up to allow a natural pitch progression. The pitch control remained constant for 30 seconds before recovery mode was engaged. To limit the results to longitudinal axis characteristics, the stall asymmetry model was inhibited for this study.

Figures 13 and 14 show pitch parameters of interest for this longitudinal study. A constant 10 degree pitch attitude was maintained until a pitch up occurred at 55 seconds. Between approximately 55 and 58 seconds, the angle of attack increased from 15 to 30 degrees while elevator deflection was held constant. A stable trim at approximately 24 degrees angle of attack followed. At about 85 seconds, the controller initiated recovery. The response to conventional recovery inputs was immediate and resulted in a minimum pitch attitude of -20 degrees, minimum normal load factor of $0.5 \mathrm{~g}$, and approximately 1,500 feet of altitude loss during the recovery phase.

This stall profile was performed with all three options for the pitch damping model. The results were nearly identical. Although the relative difference in the three pitch damping coefficient models may be significant, for this profile with the GTT simulation, the model responses did not show a significant difference. This is attributed to the contribution to total pitching moment from the dynamic pitch stability being small when compared to the contribution from longitudinal static stability.
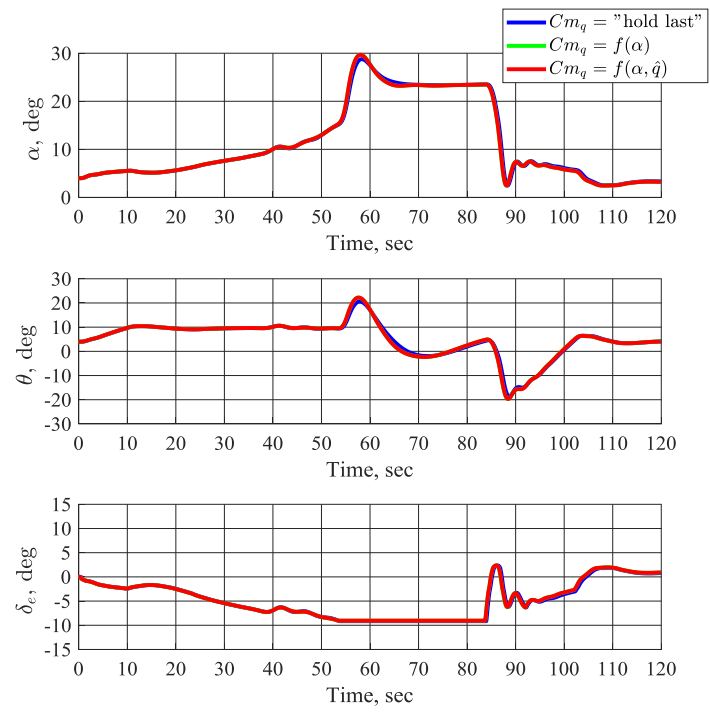

Fig. 13 Time history plots of angle of attack, pitch attitude, and elevator deflections for a 1-g stall profile are shown for various pitch damping model options.
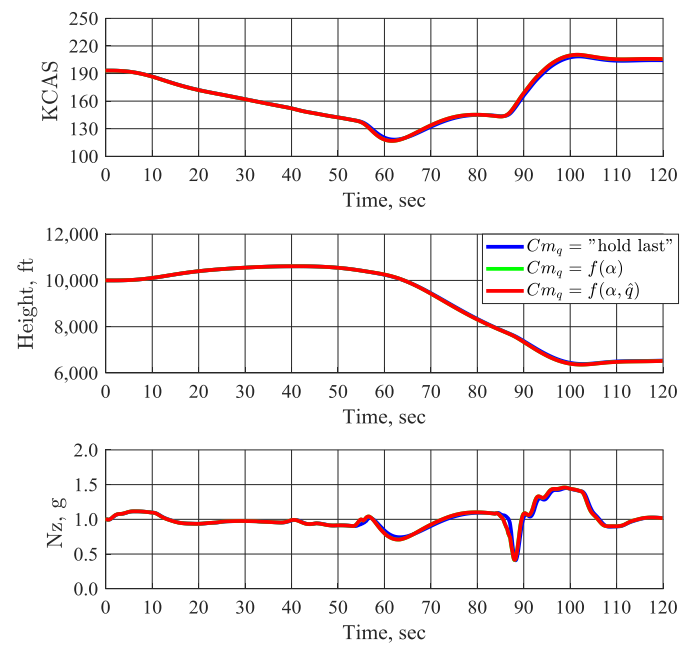

Fig. 14 Time history plots of calibrated airspeed in knots, height above ground, and normal load factor for a 1-g stall profile are shown for various pitch damping model options. 
To assess the effect of the stall asymmetry model on roll response, a piloted simulation study was performed using the Integration Flight Deck simulator cockpit in the Cockpit Motion Facility. A straight ahead 1-g stall was performed with the GTT simulation configured with center of gravity at 25\% mean aerodynamic chord. Figures 15 and 16 show time history data from the stall profile. In Fig 15, as angle of attack exceeds the threshold of 10 degrees, stick pusher activation can be noted by the abrupt elevator movement at 44 seconds. In this time history data, the elevator remains neutral until the angle of attack has stabilized. That indicates that the pilot does not interfere with the operation of the stick pusher. Figure 16 shows the bank angle and aileron deflection time history data. Stall roll off begins at about 42 seconds as angle of attack exceeds 9 degrees. The data show that the rolling motions were small and easily managed. This is attributed to the nominal operation of the stick pusher, which quickly reduced angle of attack and eliminated the rolling moment asymmetry.
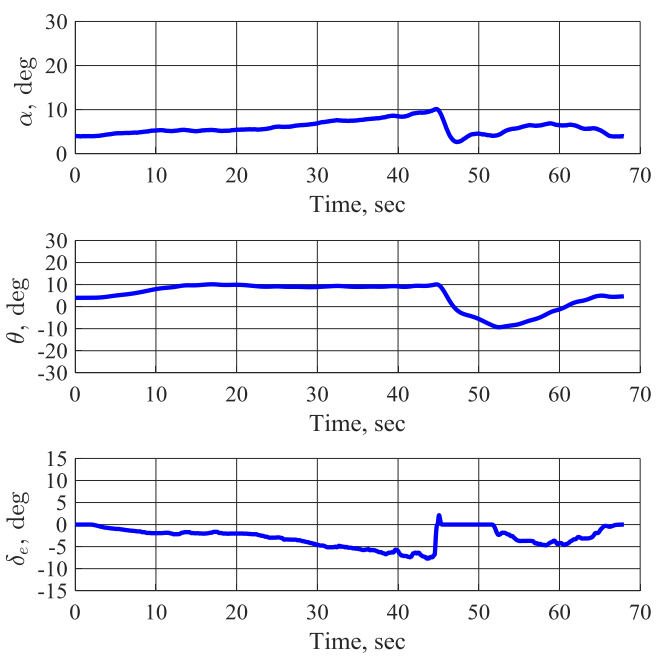

Fig. 15 Time history plots of angle of attack, pitch attitude, and elevator deflections for a 1-g stall profile with CG at $25 \%$ mean aerodynamic chord for piloted stall profile with stick pusher on and stall asymmetry model on.
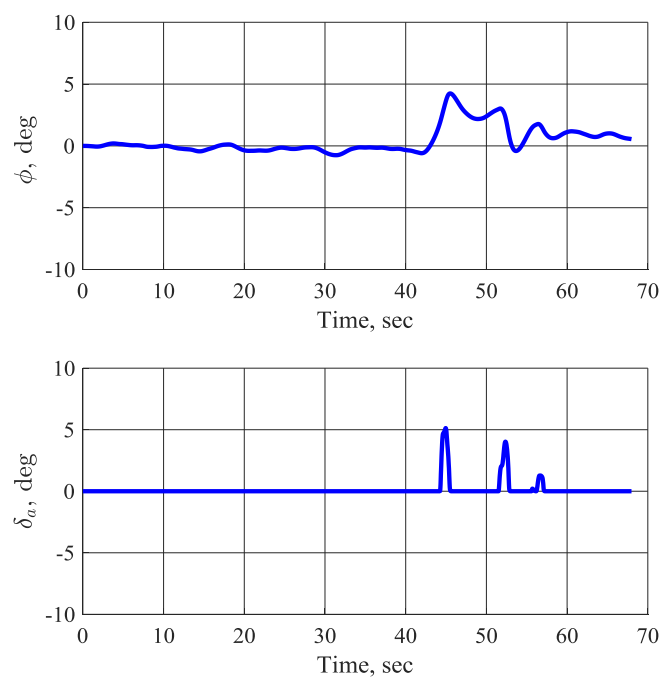

Fig. 16 Time history plots of bank angle and aileron for a 1-g stall profile with CG at $\mathbf{2 5 \%}$ mean aerodynamic chord are shown for piloted stall profile with stick pusher on and stall asymmetry model on. 
A "batch" simulation study, which used flight data from a stall upset incident, was performed. The purpose of the study was to assess the suitability of the generic T-tail airplane simulation to reproduce key dynamics during a stall upset training scenario. The incident data were digitized from a 2017 technical report. ${ }^{2}$ The report discussed and illustrated the value of using accident and incident data in the development of training scenarios for stall and upset prevention.

The incident data used in the GTT simulation analysis were recorded during a stall upset event that occurred to a Ttail regional jet transport airplane during the climb phase of flight. During the course of the incident, the left engine failed. The event transpired after a prolonged (10 minute) deceleration. The initial stall happened at an altitude of approximately 34,000 feet. The stick pusher activation took place after the stick shaker activated and the pilot applied aft control column inputs. The data in the technical report show that, as expected, the airplane pitched nose down and the angle of attack decreased to an angle below the stick shaker activation threshold. The data further show that an aggressive aft column pull followed, and the angle of attack again exceeded the stick pusher activation angle. The event data show that the cycle of an aggressive column pull following stick pusher activation continued for seven cycles. The report notes this stick pusher dynamic pattern is one that has been repeatedly seen. *

To study this scenario, the GTT simulation was trimmed in slow flight at 34,000 feet. The stall pilot algorithm, described previously, was used to slowly increase the angle of attack. As the angle of attack approached the stick shaker angle of attack, the simulation switched from stall pilot control of the pitch axis to a playback of the control column inputs from the incident flight data. During the playback, linear interpolation was used to estimate the column commands between the data points that were discretized from the technical report graphics. During simulations, the roll axis (wheel) command inputs were generated by the stall pilot algorithm. It is important to note that because the actual control surface deflections and column-to-surface command schedules were not available, the simulation's column-to-elevator command gearing schedule was tuned to obtain the comparison data.

Figure 17 shows comparisons of angle of attack, pitch attitude, and percent relative control column deflection. The percent control column commands are relative to the maximum reported for the event. In terms of both high frequency oscillation and low frequency trend, good agreement is seen for both the angle of attack and pitch attitude response. Figure 18 shows the comparison of bank angle data. Reasonable agreement is seen with respect to the high frequency oscillatory nature and left wing down trend after 20 seconds. It should be noted that without the stall asymmetry model, the simulation bank angle data would not be oscillatory. To match the left wing down trend that develops in the bank angle data after 20 seconds, a fuel cut was applied to the simulation's left engine at 13.7 degrees angle of attack. This was done because an engine failure was known to have occurred during the in-flight event. The timing of the fuel cut was empirically determined to achieve agreement with the bank angle trend data.

Although the timing of the engine fuel cut in the simulation was empirical, Fig. 19 (from Ref. 9) shows a potential physics based correlation. Figure 19 shows Mach number contours from a CFD based analysis. The figure represents a two-dimensional slice which is parallel to the airplane centerline and offset to cut through the midline of the engine nacelle. Outlines of the airfoil shape, nacelle edges, and horizontal tail can be seen in white. The blue and dark green color contours represent low speed flow, and represent the separated wing wake at 13 degrees angle of attack. It can be seen in this figure that the interaction of the separated wing wake with the nacelle is predicted. For this reason, (as discussed in section II E.) enhancement of inlet flow distortion effects in the GTT simulation's T-MATS engine model is planned.

\footnotetext{
${ }^{*}$ The event description and flight data presented herein are summarized and approximated from a public domain report (Ref. 2) and should not be taken to contradict, supersede, or elaborate on NTSB analysis and reporting.
} 

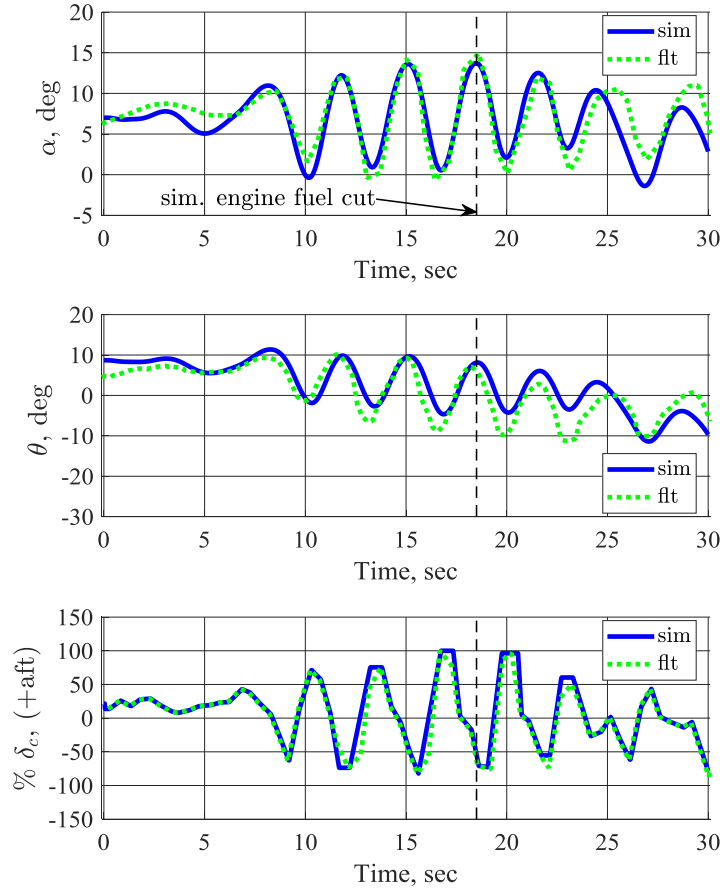

Fig. 17 Comparison of longitudinal axis GTT simulation and flight time history from Ref. 2.
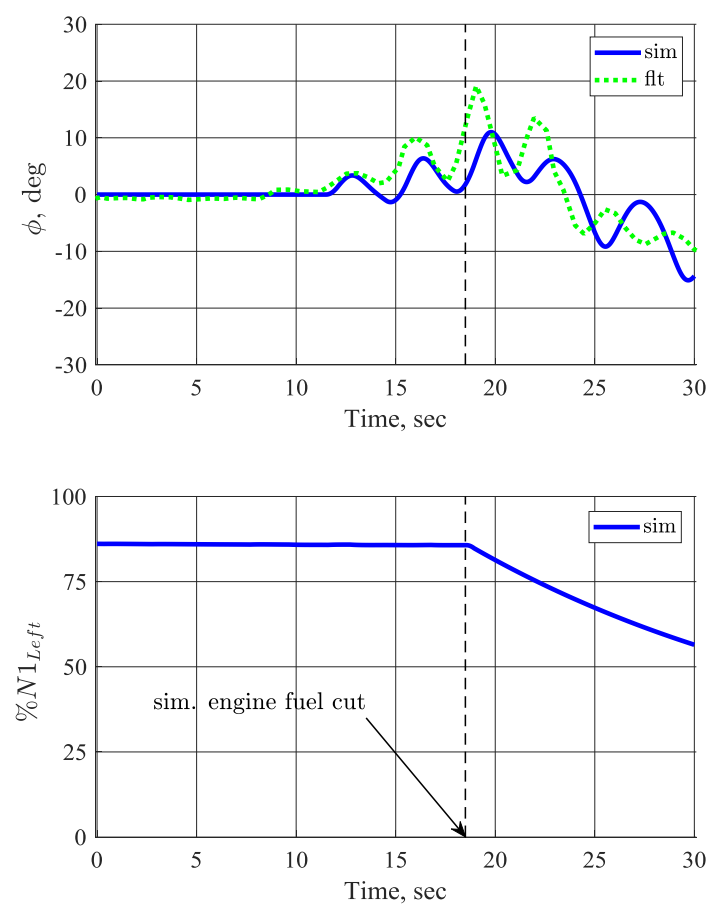

Fig. 18 GTT simulation compared to Ref. 2 flight data of bank angle, and simulation time history data of left engine fan speed.

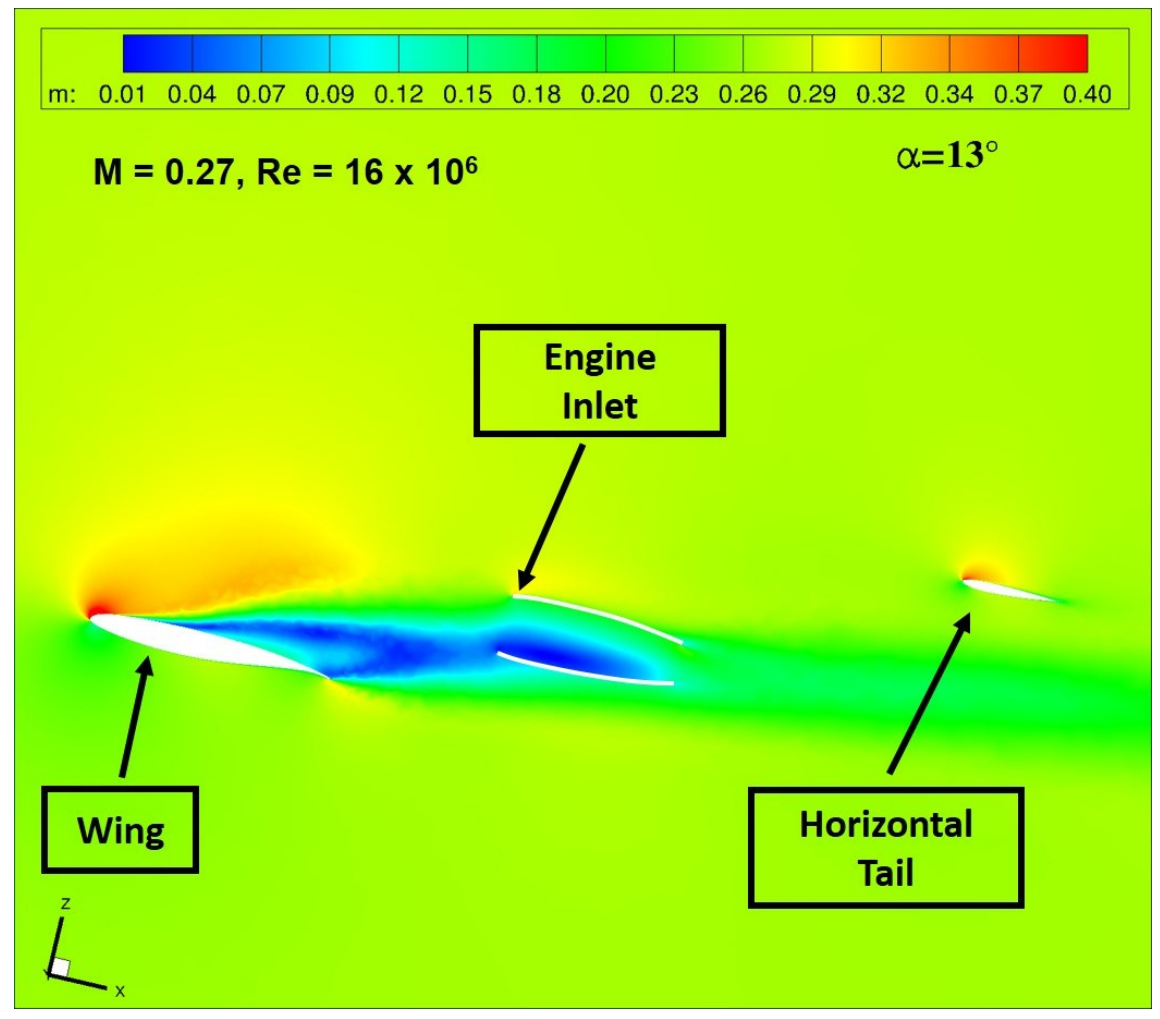

Fig. 19 Mach number contours, from a CFD solution, showing interaction of low energy wake with left engine nacelle at a 13 degrees angle of attack condition 


\section{Concluding Remarks}

Data from tunnel and CFD tests were used to develop a simulation model of a generic T-tail transport airplane. The tunnel data were acquired at low speed using static and dynamic (forced oscillation) test techniques. A full piloted simulation with stick pusher capability, was developed. The simulation model characteristics include an unstable pitch break, decreasing roll stability, decreasing control effectiveness, and un-commanded rolling motions from a stall asymmetry model as stall angle-of-attack is approached. The simulation showed conventional recovery techniques produced immediate recovery from 1 -g stalls with center of gravity at $25 \%$ mean aerodynamic chord and nominal stabilizer settings. Preliminary stall-pitch-response studies showed an insensitivity to the pitch damping model fidelity.

Future work should include exploration of dynamic response characteristics for aft center of gravity conditions, study of dynamic response sensitivities to additional dynamic model formulations, and in-depth study of lateral directional characteristics, particularly at extreme post-stall conditions. Additionally, the effect of the separated wing wake interaction with engine performance should be modeled as part of the propulsion system. The effect of the enhanced engine models on stall characteristics and stall recoverability should be studied.

\section{References}

\footnotetext{
1“Statistical Summary of Commercial Jet Airplane Accidents: Worldwide Operations 1959-2015.”, Boeing Commercial
} Airplanes. Seattle, Washington, July 2016

${ }^{2}$ Crider, Dennis A., "The Use of Data from Aviation Accident Investigations in Development of Flight Simulator Training Scenarios", AIAA 2017-1078, AIAA Modeling and Simulation Technologies Conference, AIAA SciTech Forum, January, 2017.

${ }^{3}$ Shah, Gautam H., et al., "Wind-Tunnel Investigation of Commercial Transport Aircraft Aerodynamics at Extreme Flight Conditions", SAE 2002-01-2912, World Aviation Congress \& Display, November 5-7, 2002.

${ }^{4}$ Foster, John V., et al., "Dynamics Modeling and Simulation of Large Transport Airplanes in Upset Conditions", AIAA 20055933, August, 2005.

5"Loss of Control on Approach, Colgan Air, Inc., Operating as Continental Connection Flight 3407, Bombardier DHC-8-400, N200WQ, Clarence Center, New York, February 12, 2009," Accident Report NTSB/AAR-10/01, National Transportation Safety Board, Washington DC, Feb. 2010.

${ }^{6}$ Schroeder, Jeffery A. and Burke, Robert H., "Upset Prevention and Recovery Training - A Regulator Update", AIAA 20161429, 4 January, 2016.

${ }^{7}$ Schroeder, Jeffery A., et al., “An Evaluation of Several Stall Models for Commercial Transport Training”, AIAA 2014-1002, AIAA Modeling and Simulation Technologies Conference, AIAA SciTech Forum, January, 2014.

${ }^{8}$ Grant, Peter R., et al., "Development of Post-stall Flight Models from Certification Flight Test and Wind-tunnel Data", AIAA 2017-1549, AIAA Modeling and Simulation Technologies Conference, AIAA SciTech Forum, January, 2017.

${ }^{9}$ Cunningham, K., et al., "Preliminary Test Results for Stability and Control Characteristics of a Generic T-tail Transport Airplane at High Angle of Attack", Submitted for Publication AIAA Atmospheric Flight Mechanics Conference, AIAA SciTech Forum, January, 2018.

${ }^{10}$ Leslie, R. A., Geyer, D. W., Cunningham, K., Glaab, P. C., Kenney, P. S., Madden, M. M., "LaSRS++ An Object-Oriented Framework For Real-Time Simulation of Aircraft", AIAA-98-4529, AIAA Modeling and Simulation Technologies Conference and Exhibit, August 1998.

${ }^{11}$ Madden, M.M., "Architecting a Simulation Framework for Model Rehosting", AIAA-2004-4924, AIAA Modeling and Simulation Technologies Conference, August 2004.

${ }^{12}$ Cowen, B., Stringer, M. T., Hutchinson, B.K., Davidson, P.C., and Gupton, L. E., "Current Performance Characteristics of NASA Langley Research Center's Cockpit Motion Base and Standardized Test Procedure for Future Performance Characterization," NASA/TM-2014-218148, June 2014.

${ }^{13}$ Hoh, R. H., Nicoll, T. K., and Desrochers, P., "Piloted Simulation Study to Develop Transport Aircraft Rudder Control System Requirements, Phase 2: Develop Criteria for Rudder Overcontrol," FAA report DOT/FAA/AR-10/17, November 2010.

${ }^{14}$ Chapman, J. W., Lavelle, T. M., May, R.D., Litt, J. S., Guo, T.-H., "Propulsion System Simulation Using the Toolbox for the Modeling and Analysis of Thermodynamic Systems (T-MATS)," AIAA 2014-3929, 50th AIAA/ASME/SAE/ASEE Joint Propulsion Conference, Cleveland, OH, July 28-30, 2014

${ }^{15}$ Adibhatla, S. and Karla Johnson, K. L., "Evaluation of a nonlinear PSC algorithm on a variable cycle engine," AIAA-932077, 29th Joint Propulsion Conference and Exhibit, Monterey, CA, June 28-30, 1993. 
${ }^{16}$ Jones, S. M., "Steady-State Modeling of Gas Turbine Engines Using the Numerical Propulsion System Simulation Code," GT2010-22350, Proceedings of ASME Turbo Expo 2010: Power for Land, Sea and Air, GT2010, June 14-18, 2010, Glasgow, UK.

${ }^{17}$ Kulikov, G. G., and Thompson, H. A., Dynamic Modelling of Gas Turbines: Identification, Simulation, Condition Monitoring and Optimal Control, Springer, 2005.

${ }^{18}$ Frederick, D. K., Garg. S., Adibhatla, S., "Turbofan Engine Control Design Using Robust Multivariable Control Technologies," IEEE Transactions on Control Systems Technology, Vol. 8, No. 6, November 2000.

${ }^{19}$ DeCastro, J. A., Litt, J. S., Frederick, D. K., A Modular Aero-Propulsion System Simulation of a Large Commercial Aircraft Engine, NASA/TM-2008-215303.

${ }^{20}$ Walsh, P.P., and Fletcher, P., Gas Turbine Performance, Blackwell Science/ASME, 2004.

${ }^{21}$ Liu, Y., Claus, R.W., Litt, J. S., Guo, T.-H., "Simulating Effects of High Angle of Attack on Turbofan Engine Performance," AIAA 2013-1075, 51st AIAA Aerospace Sciences Meeting including the New Horizons Forum and Aerospace Exposition, Grapevine, TX, January 7-10, 2013.

${ }^{22}$ Kopasakis, G., Cheng, L., and Connolly, J. W., "Stage-by-Stage and Parallel Flow Path Compressor Modeling for a Variable Cycle Engine", AIAA 2015-4143, 51st AIAA/SAE/ASEE Joint Propulsion Conference, AIAA Propulsion and Energy Forum, July 27-29, 2015, Orlando, FL.

${ }^{23}$ National Transportation Safety Board, "Crash of Pinnacle Airlines Flight 3701, Bombardier CL-600-2B19, N8396A, Jefferson City, Missouri, October 14, 2004," Aircraft Accident Report NTSB/AAR-07/01. Washington, DC, 2007.

${ }^{24}$ Frink, N. T., Murphy, P.C., Atkins, H.L., Viken, S., Petrilli, J. L., Gopalarathnam, A., and Paul, R. C., "Status of Computational Aerodynamic Modeling Tools for Aircraft Loss-of-Control - Invited", AIAA 2016-1041, AIAA Atmospheric Flight Mechanics Conference, AIAA SciTech Forum, January 4-8, 2016, San Diego, CA.

${ }^{25}$ Kennedy, S., Robinson, T., Spence, S., Richardson, J., Computational Investigation of Inlet Distortion at High Angles of Attack, Journal of Aircraft, Vol. 51, No. 2, March-April 2014.

${ }^{26} \mathrm{http}: / /$ www.openvsp.org/, accessed 10/20/2017.

${ }^{27} \mathrm{https}$ ://software.nasa.gov/software/LAR-17595-1, accessed 11/3/2017. 